\title{
The picture superiority effect in a cross-modality recognition task
}

\author{
GEORG STENBERG and KARL RADEBORG \\ University of Lund, Lund, Sweden \\ and \\ LEIF R. HEDMAN \\ University of Lund, Lund, Sweden \\ and Telia Research, Malmö, Sweden
}

\begin{abstract}
Words and pictures were studied, and recognition tests were given in which each studied object was to be recognized in both word and picture format. The main dependent variable was the latency of the recognition decision. The purpose was to investigate the effects of study modality (word or picture), of congruence between study and test modalities, and of priming resulting from repeated testing. Experiments 1 and 2 used the same basic design, but the latter also varied retention interval. Experiment 3 added a manipulation of instructions to name studied objects, and Experiment 4 deviated from the others by presenting both picture and word referring to the same object together for study. The results showed that congruence between study and test modalities consistently facilitated recognition. Furthermore, items studied as pictures were more rapidly recognized than were items studied as words. With repeated testing, the second instance was affected by its predecessor, but the facilitating effect of picture-to-word priming exceeded that of word-to-picture priming. The findings suggest a two-stage recognition process, in which the first is based on perceptual familiarity and the second uses semantic links for a retrieval search. Common-code theories that grant privileged access to the semantic code for pictures or, alternatively, dual-code theories that assume mnemonic superiority for the image code are supported by the findings. Explanations of the picture superiority effect as resulting from dual encoding of pictures are not supported by the data.
\end{abstract}

A long tradition in memory research has favored the use of verbal material. Studies that have departed from this tradition by using pictorial material have uncovered important differences in the ways pictorial and verbal items are processed and remembered.

Pictures show a memory superiority over words in both recognition (Shepard, 1967; Standing, Conezio, \& Haber, 1970) and recall (Bousfield, Esterson, \& Whitmarsh, 1957). The impressive performance of the subjects in Shepard's study, who recognized $87 \%$ out of several hundred pictures in a forced-choice test after 1 week, far exceeds what is normally encountered in verbal memory. Some phenomena that are routinely found in verbal memory, such as the serial position effect, prove to be absent in memory for pictures (Potter \& Levy, 1969; Shaf-

This study was supported by a grant from Telia AB, Farsta, Sweden. G.S. was also supported by a grant from the Swedish Council for the Humanities and Social Sciences. We wish to thank Margaret Jean Intons-Peterson, Judith Kroll, Douglas Nelson, Allan Paivio, Joan Gay Snodgrass, and Kathryn Spoehr for their helpful comments. We are also grateful to Kaj Sunesson (Experiment 2), Staffan Hjorth and Henrik Svenstam (Experiment 3), Camilla Lindgren (Experiment 4), and Stefan Johansson (pilot testing) for their help in performing the experiments. Correspondence should be addressed to G. Stenberg, Department of Clinical Neurophysiology, University Hospital, S-221 85 Lund, Sweden (e-mail: georg.stenberg@psykol.lu.se). fer \& Shiffrin, 1972). In addition, on-line processing tasks have shown differences in reaction times (RTs). Categorization is faster for pictures, and naming is faster for words (Potter \& Faulconer, 1975; Smith \& Magee, 1980).

The findings of picture/word differences have added fuel to the more general debate concerning the representation of knowledge in memory. The unresolved issue in this debate is whether items in long-term memory are stored in a unitary abstract form, divested of the form in which they originally entered the perceptual apparatus. Proponents of this idea (Anderson \& Bower, 1973; Pylyshyn, 1973) suggest that both visual and verbal information is stored in a single, amodal form, where the constituents of memory are represented as abstract concepts and propositions.

Opponents of the single-code view advocate the existence of at least two types of memory storage: one verbal and another nonverbal, or imaginal (Paivio, 1971). The mode of stimulus presentation largely determines which store will be used; thus, pictures are predominantly encoded nonverbally, and words, whether presented visually or auditorily, are encoded verbally. The two storages are, however, assumed to be interconnected and can therefore support each other in recall and recognition. Pictures can be named and thereby gain access to verbal storage as well as nonverbal, and the referents of (concrete) words can be imagined. Items that are en- 
coded in both types of storage have a greater likelihood of being retrieved.

Hybrid models have also been introduced (Potter, 1979; Snodgrass, 1984). Snodgrass proposed the existence of three types of memory storage: an amodal, propositional one and two modality-specific stores, containing the characteristic surface representations of words and pictures, respectively. According to this view, tasks requiring semantic knowledge (i.e., knowledge about the properties of objects) are performed by accessing the propositional memory store, whereas tasks requiring knowledge of the phonology of words (or the visual appearance of pictures) are solved by recourse to the appropriate modality-specific store.

Some physiological and neuropsychological data concerning the brain activity underlying imagery have been brought to bear on these issues (Farah, 1989). This type of evidence has been concerned with what happens in the brain when objects are imagined or recalled in the absence of external stimuli. If imagery induces modality-specific activity of the same kind as that normally evoked by perception of the corresponding external object, commoncode theories are presented with a difficult challenge. Event-related potential experiments have, indeed, shown that activity over visual cortex is evoked by imagining the referents of concrete words (Farah, Weisberg, Monheit, \& Peronnet, 1989), and studies of cerebral blood flow have likewise shown that the probing of visual memories activates visual parts of the brain in contrast to more abstract memory tasks (Goldenberg, Podreka, \& Steiner, 1990). Similarly, patients with brain lesions show deficits in imagery that parallel their specific perceptual deficits (Bisiach \& Luzzatti, 1978). In a neuropsychological case study, Hart and Gordon (1992) found a pattern of deficits in a patient that indicated that some knowledge is normally represented in two independent systems: one language-based and one visually based.

However, the original, and most conspicuous, evidence of differences in memory storage for pictures and words is to be found in the memory performance data. The picture superiority effect is a robust finding across several different memory tasks. It is readily accommodated by dual-code theories, because the observed differences in memory retention are, at least at first glance, more compatible with the assumption of two different memory stores than with the assumption of just one. However, the proposed existence of two memory stores does not in itself explain why one should show superior memory characteristics over the other. In his dual-code theory, Paivio (1971, 1986, 1991) has proposed two different explanations. The first rests on the greater benefit for pictures of access to two memory stores and will here be referred to as the dual-encoding hypothesis. On presentation, many pictures are likely to be spontaneously named, which results in two memory traces instead of just one, with a consequent increased probability of retrieval. Words may be similarly dually encoded if accompanied by visual imagery, but this is less likely to occur spontaneously. The hypothesis is well compatible with the findings of retrieval rates being higher for pictures than for concrete words, and higher for concrete words than for abstract words (Paivio \& Csapo, 1973). The assumption that pictures are always named has, however, been called into question on the basis of other data (Kroll \& Potter, 1984). The second explanation claims a mnemonic superiority for the imaginal memory code per se, resulting in better memory for pictures than for words, even if only one code is used for each type of item. The first explanation is the more frequent one in discussions of dual-code theory, but empirical findings have not made it possible to exclude either alternative, and the choice is left open in recent statements of the theory (see discussion in Paivio, 1991, especially chapter 5).

For common-code theories, the picture superiority findings present a difficulty, because the assumption of uniform storage by itself is not compatible with the fact that modality of entry causes consistent differences in longterm memory accessibility. Various explanations have been proposed for this apparent discrepancy.

First, it has been proposed that access to semantic features is faster and more direct from pictures than from words (Nelson, Reed, \& McEvoy, 1977; Smith \& Magee, 1980). This hypothesis is well compatible with some observed RT differences in semantic tasks, such as categorization (Potter \& Faulconer, 1975; Smith \& Magee, 1980 ). If the processing of pictures normally attains deeper levels than does the processing of words, then the levelsof-processing approach (Craik \& Lockhart, 1972) can be invoked to explain the differences in memory performance. According to this view, deeper (in the sense of more semantic) processing leads to better retention of the processed material.

Second, it can be claimed that the sensory qualities of pictures are more distinctive and varied than are those of words. By recourse to the encoding-specificity principle (Tulving \& Thomson, 1973) or the more recent transferappropriate processing approach (Roediger, 1990), such differences could help explain superior memory for pictures, because greater distinctiveness would lead to greater informational overlap between retrieval cues and studied representation. The sensory-semantic model of Nelson and associates (Nelson et al., 1977) makes use of both this type of argument and the previous one.

Third, pictures may be subjected to more elaborate, although not necessarily deeper, processing than words, resulting in better memory retention - a formulation consonant with Craik and Tulving's (1975) revision of the levels-of-processing approach. In Snodgrass's (1984) hybrid model, processing at a presemantic level runs different courses for pictures and words. Incoming perceptual information is made to match stored prototypical images, visual or acoustic. It is a further tenet that the degree of mismatch between a perceived image and its corresponding stored internal prototype is greater than that between a perceived word and its corresponding prototype. The accumulation of mismatch information is therefore greater for pictures, leading to more extensive processing and better subsequent memory retention. In 
Snodgrass's model, the polysemy of words is also a causal factor, because a word is more likely to distribute its resultant activation over several sematic memory nodes than a picture is, and this fact increases the probability of recognition failures for words.

Interestingly, it has been shown that the picture superiority effect, although pervasive in most conventional memory tests, does not necessarily apply to some indirect (implicit) tests, where retrieval cues have a verbal format (Weldon \& Roediger, 1987; Weldon, Roediger, \& Challis, 1989). If the processing required by the test is data-driven as opposed to conceptually driven, successful retrieval is heavily dependent on making use of perceptual similarities between the retrieval cue and the studied item. The perspective that emphasizes congruence of operations between study and test has been called the transfer-appropriate processing approach, proposed and elaborated by Roediger and associates (e.g., Roediger, 1990). As applied to memory differences between pictures and words, the approach makes picture superiority conditional on the kind of processing required for retrieval. The thrust of the transferappropriate processing approach has been toward preserving the unity of memory, against, for example, the assumption of separate memory systems for explicit and implicit memory. In the present context, however, it can be said to take a middling position between single- and dual-code theories, because the approach clearly presupposes that much of the perceptual content of studied material is preserved in memory. In its explanation of picture superiority in conceptually driven tests, such as recall and recognition, it relies on the point made by Nelson and others that access to the semantic level is more efficient from pictures than from words. Thus, the more conceptual encoding of pictures conforms better with the conceptual nature of most traditional, explicit tests of memory than does the encoding of words.

The present study aims to examine the picture superiority effect in the light of some of the hypotheses referred to above. It uses a recognition test design, where concepts (corresponding to concrete words such as elephant or pipe) are presented for study in either a picture or a word format. In the ensuing recognition test, subjects are instructed to respond to recognized items in both their original and a translated form - that is, for example, if the word elephant has been studied, both the word and a picture of an elephant are items to be recognized and responded to in the memory test. Studied items are mixed with foils of new items in both modalities. The critical variable of interest is RT for the recognition decision.

The dual-encoding hypothesis builds its explanation of the picture superiority effect on the assumption that pictures are dually encoded more often than are words. This study aims to investigate that assumption. If the alleged dual encoding of pictures takes place, items studied as pictures and subsequently recognized as words should be responded to more quickly than items studied as words and recognized as pictures. In the former case, encoding in the verbal store has already taken place at the time of learning, whereas the latter case requires a process at recognition that, after activating the original trace, finds a corresponding item in the opposite store. It is assumed that this process adds time to the recognition RT.

The design generates four types of stimuli to be recognized, resulting from the crossing of study modality (picture/word) with test modality. This allows assessment of the effect of presentation modality at encoding (studied as pictures vs. studied as word), independently of modality at recognition. It also allows assessment of the effect of congruence between learning and testing modalities.

The choice of RT as the main dependent variable merits a comment, because it is not typical of episodic memory studies. Outside of the Sternberg paradigm, RT is rarely used to assess direct episodic memory. However, in the present context, it offers possibilities not easily attained by more conventional measures. First, it can be used to assess whether the critical cross-modal translation stage from picture to word can be omitted during test, because it has been anticipated during study. More generally, the latency of the recognition decision offers an index of the availability of the memory trace, supplementing the dichotomous categorization of the response as true or false. Indeed, this aspect of the retrieval may not be accessible to the subject's own awareness, although the result of the process is. In recent years, the distinction between explicit and implicit memory has attracted considerable interest (Richardson-Klavehn \& Bjork, 1988; Roediger, 1990; Schacter, 1987). The defining characteristic of direct (explicit) tests of memory is that their instructions make explicit reference to a prior learning episode, from which the subject is expected to retrieve memories. Indirect (implicit) tests, on the other hand, ostensibly test something else, such as the ability to complete word fragments, while indirectly assessing memory of a prior study episode through its influence on performance of the assigned task. The justification for the great theoretical interest devoted to the distinction is not, however, this methodological point but rather the implication that the underlying memory phenomena are different, explicit memory being accessible to subjective awareness, whereas implicit memory is not. As usefully pointed out by Richardson-Klavehn and Bjork (1988), the direct/indirect and explicit/implicit distinctions can be kept conceptually separate. Direct tests may tap into both explicit and implicit memory, such as when the encoding of test probe items in a direct test is made more fluent by the implicit memory of their previous occurrence in a study episode. Thus, both explicit and implicit memory processes may contribute to performance in a direct test, such as recognition. The conjoint contributions of explicit and implicit processes to recognition performance may lead to memory illusions, a phenomenon that has been explored by Jacoby and colleagues in a series of studies (e.g., Jacoby \& Whitehouse, 1989). 
In the present study, recognition latency may indicate processes such as fluency in the encoding of the test probes, of which subjects normally do not have full awareness. In this respect, the study has something in common with studies of priming between pictures and words (e.g., Bajo, 1988; Brown, Neblett, Jones, \& Mitchell, 1991; Carr, McCauley, Sperber, \& Parmelee, 1982). Priming studies have typically investigated facilitatory effects of previous experiences on processes such as naming or categorization. In this study, effects on the latency to make a recognition decision are at the center of interest. Thus, although measured in the context of a prototypical direct memory task (recognition), the dependent variable may be sensitive to influences of implicit memory as well. It is therefore of interest to determine whether the picture superiority effect applies to this measure, in addition to more traditional measures of recognition accuracy.

The purpose of the present study is fourfold. First, it tests whether the picture superiority effect applies to recognition reaction time - that is, do items studied as pictures enjoy an advantage in recognition speed, across both picture and word test presentations, relative to items studied as words? Second, it examines the dual-encoding hypothesis by comparing the speed with which studied items are recognized in a cross-modally translated form. The dual-encoding hypothesis predicts an advantage for pictures in this respect. Third, it examines the effect of congruence/incongruence between study and test presentation form on the speed and accuracy of the recognition decision. Completely amodal long-term storage would entail a null effect for this factor. Fourth, it examines the effect of repeated testing. Because each studied item is tested twice, once in each format, the first presentation may affect the speed with which the second is processed. Moreover, the repetition effect may be asymmetrical, in that initial testing in picture format may affect subsequent word testing differently from the reverse order. We use the term repetition priming for this effect, because it concerns the effect of previous experience (the first test instance) on later performance (the second test instance), in a task where instructions make no reference to the previous experience. (Instructions refer to what has been seen in the study phase, not what has been seen earlier in the test phase.)

\section{EXPERIMENT 1}

The first two experiments used the same basic design of speeded cross-modal recognition, as described above. The difference between them was that Experiment 1 used only a brief (4-min) retention interval, whereas Experiment 2 varied the retention interval between two groups of subjects.

To allow for the possibility of implicit naming of pictures that is crucial to the main hypothesis of the study, a long (3-sec) interstimulus interval (ISI) was used in the study phase, because earlier studies (Paivio \& Csapo, 1969) have shown that fast presentation rates may prevent naming from taking place.

\section{Method}

Materials. Stimulus material was selected from the set of pictures published by Snodgrass and Vanderwart (1980). This set of 260 black-and-white line drawings-of animals, tools, furniture, and other everyday objects - has been designed to achieve a relative homogeneity of visual appearance, as regards size, orientation, and so on. The objects of the pictures have been chosen to avoid equivocation, and data on interindividual consistency in naming are given in the original article. Although the nameconsistency data, for obvious reasons, apply only to the English language, naming of these common objects appears to be relatively unequivocal in other (related) languages as well. All verbal material in these experiments was given in Swedish, and, for the present purposes, it was reasonably uncomplicated to establish a one-to-one correspondence between pictures and their Swedish names, with a few exceptions, noted below.

A set of 80 items was selected to make up the stimulus material. From this set, 20 pictures and 20 words (not referring to the same objects as the pictures) were chosen as the items to be studied. Twenty other pictures and 20 other words served as foils in the recognition test.

All stimuli were presented on the screen of an Apple Macintosh SE computer. The pictures were saved, after being scanned from paper copies, in 1-bit/pixel (black-and-white) graphics files and displayed under program control on the center of the screen, occupying approximately a $4 \times 4 \mathrm{~cm}$ area. The words were likewise displayed centered on the screen, in a large (24-point) typeface, so that a typical word occupied a $3 \times 1 \mathrm{~cm}$ area. At an estimated average viewing distance of $60 \mathrm{~cm}$, the stimulus sizes corresponded to horizontal viewing angles of about $3^{\circ}$ for the words and $4^{\circ}$ for the pictures.

Subjects. Thirteen students ( 1 man, 12 women), 19-31 years old, at the Psychology Department of the University of Lund participated and were paid for their participation.

Procedure. Before the study phase of the experiment, the subjects were informed that both words and pictures were to appear on the screen, and they were asked to try to remember as much as possible of what they saw. During the study phase, the selected 20 words and 20 pictures were shown, in randomized order, each for $3 \mathrm{sec}$, followed by a 3-sec ISI, during which a fixation cross was displayed. The 40-stimuli sequence was repeated three times.

After a 4-min break, the test phase began. Before the test sequence, the subjects were instructed to press the mouse button of the computer for all items that they recognized from the study phase. A "no" decision required no response. It was emphasized that words and pictures designating the same object were to be regarded as equivalent, and this point was explained by examples (not taken from the stimulus material). It was also emphasized that both speed and accuracy were important.

During testing, each stimulus was displayed on screen for $2 \mathrm{sec}$, followed by a 2.5 -sec ISI with a fixation cross. To be counted as valid, a buttonpress had to occur during the $2-\sec$ stimulus display period.

The previously studied objects appeared twice each, once in word format and once in picture format, in randomized order and intermingled with the distractors, which appeared once each. The average number of intervening items between the two presentations of a studied item was 40 . Responses were timed by the computer, and all responses were saved to a file for later analysis.

Data analysis. Here, as in the following experiments, results based on designating subjects as the random factor are combined with those based on items as the random factor, using the $\min F^{\prime}$ quasi- $F$ ratio, as suggested by Clark (1973). The mean standard error values are those provided by the by-subjects analysis. The significance level is .05 .

\section{Results}

Responses were collected from four types of stimuli. For the sake of convenience, these will be referred to as 
WP, WW, PP, and PW, where the first letter designates modality during the study phase (word/picture), and the second designates testing modality. For all four types, both RTs and accuracy statistics were computed. In the analyses of variance (ANOVAs), one factor was modality congruence - that is, whether or not the test stimulus had the same modality as the previously studied item (categories WW and PP vs. WP and PW). Another factor was the modality in which the item had been encountered during study (i.e., categories $\mathrm{PW}$ and PP vs. WP and WW). A third factor in the RT analysis was the repetition effect. Because each studied concept was tested on two (not immediately contiguous) occasions, one in each format, each test item was either a first or a second test instance. In the latter case, it was preceded somewhere in the test sequence by its cross-modal counterpart. For example, a studied picture of an elephant could be tested by the word elephant first and, some time later, by the originally studied picture. Because repeated testing could affect responses, in that the second instances could be processed differently from the first, the repetition factor was brought into the analysis.

Reaction time. For each stimulus category, average RTs were computed across all correct responses. Median RTs were also computed to protect against undue influence of outliers. However, since the median RTs led to the same conclusions as the average RTs, only the latter will be reported.

The effect of study/test congruence proved to be reliable $\left[\min F^{\prime}(1,75)=32.28, M S_{\mathrm{e}}=5,873\right]$. Congruence conferred a large advantage in recognition speed (695 vs. $862 \mathrm{msec}$ ). In addition, there was a reliable effect of study modality $\left[\min F^{\prime}(1,80)=5.88, M S_{\mathrm{e}}=4,497\right]$. Items that had been studied in the picture modality were recognized more quickly than those that had been studied as words (744 vs. $812 \mathrm{msec}$ ). The three-way interaction congruence $\times$ study modality $\times$ repetition $\left[\min F^{\prime}(1,84)=15.04, M S_{\mathrm{e}}=2,443\right]$ indicated different repetition effects for different types of test stimuli. As can be seen in Table 1, word test items showed facilitated recognition when being preceded by their picture counterparts, but recognition of pictures was not facilitated by prior presentation of word counterparts. Mean picture-to-word priming was $130 \mathrm{msec}$, whereas mean word-to-picture priming was inhibitory $(-80 \mathrm{msec})$.

To evaluate predictions from the dual-coding model, it is important to inspect the differences between translated (i.e., study/test incongruent) and unaltered (i.e., study/test congruent) test item presentations. If studied pictures tend to be dually encoded, both verbally and nonverbally, more often than studied words, they will be at an advantage at cross-modal testing. In terms of the test item categories, the PW type should be less disadvantaged in relation to the PP type than should the WP type in relation to the WW type. That would result in a significant congruence $\times$ study modality interaction term. However, in the overall ANOVA, both the by-subjects $F 1$ and the by-items $F 2$ were less than
Table 1

Reaction Times (in Milliseconds) in Experiment 1

\begin{tabular}{lrrrr}
\hline & \multicolumn{4}{c}{ Targets } \\
\cline { 2 - 5 } & PP & WW & PW & WP \\
\hline As first test instance & 639 & 765 & 912 & 847 \\
As second test instance & 693 & 684 & 734 & 953 \\
Repetition effect & -54 & 82 & 178 & -106 \\
\hline
\end{tabular}

Note-Test stimulus types are designated by two letters, the first of which refers to study modality, and the second, to test modality (e.g., $\mathrm{PW}=$ picture/word). Thus, $\mathrm{PW}$ indicates a word test probe referring to an item studied in picture format. Each studied item was tested twice, once in each modality. Therefore, the category "PW, as second test instance" designates PW stimuli that have been preceded in the test sequence by PP stimuli referring to the same studied item. The repetition effect is the difference in reaction time between those test stimuli appearing before and those appearing after their cross-modal counterparts.

1 , and so was, consequently, the more conservative $\min F^{\prime}$.

But the congruence $\times$ study modality interaction includes both primed and unprimed test items, and there is therefore a risk of confounding the asymmetric pictureto-word and word-to-picture effects with those of the actual translation process. A more appropriate comparison may therefore be one where only first-show, unprimed test items are included. By this token, the PW-PP differences and the WP-WW differences were computed for the unprimed items. These quantities will be labeled translation costs, since they measure the extra processing time required for stimuli when they appear in a different form from that in which they were studied. The analysis showed that translation costs were greater for the items studied as pictures than for those studied as words [ 273 vs. $\left.82 \mathrm{msec} ; F(1,12)=24.18, M S_{\mathrm{e}}=9,812\right]$. This is in contrast with the dual-encoding hypothesis, which predicts the opposite outcome.

Accuracy. Although the experiment was designed to give a large proportion of correct responses in order to maximize the number of usable RTs, performance was less than completely correct, and there was some variation between stimulus types. Hit rates and false-alarm rates are given in Table 2, as well as $d^{\prime}$ measures of sensitivity, computed with the correction recommended by Snodgrass and Corwin (1988).

The $d^{\prime}$ 's were subjected to a 2 (congruence) $\times 2$ (study modality) ANOVA. The factor of study/test congruence proved to be a reliable source of variation $[F(1,12)=$ $\left.35.77, M S_{\mathrm{e}}=0.09\right]$. Test items were more accurately recognized in their studied form. In this, and some other respects, the accuracy results parallel those for the RTs. There was a tendency for items studied as pictures to be better recognized, but the difference was not significant $(p=.16)$.

For the foils, false-alarm rates tended to differ with modality. Picture foils were more likely to be falsely accepted as old; however, in the ANOVAs, the difference was significant only in the by-subjects analysis $[F 1(1,12)$ $\left.=5.33, M S_{\mathrm{e}}=0.001\right]$. 
Table 2

Hit Rates, False-Alarm Rates, and $d^{\prime}$ 's in Experiment 1

\begin{tabular}{cccc}
\hline & Hit Rate & $d^{\prime}$ & $\begin{array}{c}\text { False-Alarm } \\
\text { Rate }\end{array}$ \\
\hline Targets & & & \\
PP & .99 & 3.60 & \\
WW & .94 & 3.57 & \\
PW & .92 & 3.28 & \\
WP & .87 & 2.90 & \\
Foils & & & .04 \\
Picture & & & .00 \\
Word & & & \\
\hline
\end{tabular}

Note-Abbreviations explained in Table 1 note and in text.

\section{Discussion}

The RT results indicate that perceptual similarity between study and test facilitated recognition of the underlying concept and that, therefore, some modalityspecific factor takes active part in the recognition process. Furthermore, there was a picture superiority effect, analogous to the one often found with accuracy results. Both of these findings are well compatible with dual-code theory or, alternatively, with common-code theories that grant a privileged status to pictures in access to semantic memory. The particular dual-encoding explanation of the picture superiority did not, however, fare well with comparisons of translation costs for studied pictures and studied words. They were equivalent if both primed and unprimed items were included, and they were larger for pictures if only unprimed items were included. In either case, the prediction of speedier (because preempted during study) translation of pictures was not upheld.

A striking aspect of the data was the size and asymmetry of the repetition effects during testing. Quite substantial facilitation $(130 \mathrm{msec})$ took place in one direction (picture-to-word), but not in the other. Typical findings in earlier research have suggested that effective priming demands a high degree of perceptual similarity between prime and target. In the present highly conceptual task, cross-modal priming took place, an intriguing aspect of which was its asymmetry of direction. Discussion of the implications of these findings will be deferred to the General Discussion section.

The value of the accuracy results is limited by the deliberately restricted range of near-ceiling performance. However, what variation there was seemed to concur with that of the RTs, thus militating against speedaccuracy tradeoffs as an explanation for the RT findings. Instead, a common function, such as strength of trace, seems to underlie both measures.

\section{EXPERIMENT 2}

Taking into consideration the brief interval between learning and testing in Experiment 1, it could be argued that an undue advantage was given to modality-specific and relatively evanescent forms of memory and that letting a longer interval elapse before testing might facili- tate a putative transition toward an amodal and more permanent storage. Experiment 2 was designed to test this, using two groups, one of which underwent the same procedure as in Experiment 1, whereas the other was occupied by a distraction task during 20 min before testing.

\section{Method}

Materials and Procedure. The task used to occupy the delayed-recognition group between study and recognition was a 25 -item test taken from a commercial intelligence assessment battery (Deltabatteriet; Testförlaget). It requires completion of arithmetic series, loads heavily on reasoning and arithmetic abilities, and was chosen primarily for its absence of potentially interfering verbal or imaginal components.

The stimulus material and the procedure for the main task was identical to that used in Experiment 1, except for a substitution of a small number (6) of stimulus items. In postexperimental interviews, the subjects in Experiment 1 had commented that some of the pictures did not correspond to the intended Swedish word unequivocally. Closer inspection showed that minor language and cultural differences in relation to the published American norms (Snodgrass \& Vanderwart, 1980) caused these discrepancies. The ambiguous items were replaced by others from the same material for Experiment 2.

Subjects. A total of 31 students were paid to participate. They were randomly assigned to either the immediate-recognition group ( 4 men, 11 women) or the delayed-recognition group ( 8 men, 8 women).

\section{Results}

Analysis of Experiment 2 was performed along the same lines as in Experiment 1, with the addition of retention interval as a between-subjects factor.

Reaction time. There were no significant effects involving retention interval, either alone or in interaction. Therefore, mean RTs for test item types are presented in Table 3 averaged over retention interval groups. The within-subjects factors repeated the pattern of results from Experiment 1. Thus, the main effect of congruence was reliable $\left[\min F^{\prime}(1,101)=53.09, M S_{\mathrm{e}}=11,129\right]$, and so was the main effect of study modality $\left[\min F^{\prime}(1,96)=\right.$ 17.00, $\left.M S_{\mathrm{e}}=5,215\right]$. As in Experiment 1, their interaction did not approach significance (both $F 1$ and $F 2$ less than 1). The congruence $\times$ study modality $\times$ repetition interaction was reliable $\left[\min F^{\prime}(1,98)=5.58, M S_{\mathrm{e}}=\right.$ 6,719 ], with the same pattern as in Experiment 1-that is, facilitation from picture-to-word test items $(66 \mathrm{msec})$, but an inhibitory effect from word-to-picture test items $(-43 \mathrm{msec})$.

The translation costs (computed as in Experiment 1; i.e., PW-PP and WP-WW for unprimed items only) were $232 \mathrm{msec}$ for items studied as pictures and $123 \mathrm{msec}$

Table 3

Reaction Times (in Milliseconds) in Experiment 2

\begin{tabular}{llrrr}
\hline & \multicolumn{4}{c}{ Targets } \\
\cline { 2 - 5 } & PP & WW & PW & WP \\
\hline As first test instance & 679 & 820 & 911 & 942 \\
As second test instance & 724 & 759 & 839 & 983 \\
Repetition effect & -45 & 61 & 72 & -41 \\
\hline
\end{tabular}

Note-Abbreviations explained in Table 1 note and in text. 
for items studied as words. The effect of study modality was reliable $\left[F(1,29)=13.54, M S_{\mathrm{e}}=13,670\right]$. There was no difference between retention interval groups. If both primed and unprimed items were included, translation costs were equal, as shown by the nonsignificant congruence $X$ study modality interaction in the main ANOVA (both $F 1$ and $F 2$ less than 1).

Accuracy. Hit rates and false-alarm rates are presented in Table 4, along with $d^{\prime}$ measures of detection sensitivity. Results are presented for the retention interval groups separately, because there were some differences between them.

In the analysis of $d^{\prime}$, reliable main effects of congruence $\left[F(1,29)=26.24, M S_{\mathrm{e}}=0.076\right]$ and study modality $\left[F(1,29)=8.38, M S_{\mathrm{e}}=0.246\right]$ indicated that congruent and picture-studied items were recognized more accurately. These effects parallel those for RTs. In addition, there was a congruence $\times$ study modality interaction $\left[F(1,29)=5.78, M S_{\mathrm{e}}=0.127\right]$ due to lower recognition accuracy for WP items. There was also an interaction effect of congruence $\times$ study modality $\times$ retention interval $\left[F(1,29)=6.44, M S_{\mathrm{e}}=0.127\right]$, indicating that recognition of items presented as words during test was improved in the delayed-recognition group.

A separate examination of false-alarm rates revealed a difference between groups $\left[F(1,29)=4.23, M S_{\mathrm{e}}=\right.$ 0.003 ] because of increased false-alarm rates in the delayed-recognition group. The two foil modalities differed in their capacity to evoke false recognition responses $\left[F(1,29)=13.54, M S_{\mathrm{e}}=0.001\right]$. In both groups, picture foils were more likely to be called old.

\section{Discussion}

The results of Experiment 2 generally confirm those of Experiment 1. Concerns could be allayed regarding the stability of the RT results over a modestly extended retention interval. No restructuring of the memory codes seemed to take place during the delay.

Table 4

Hit Rates, False-Alarm Rates, and $d^{\prime}$ 's in Experiment 2

\begin{tabular}{ccc}
\hline & $\begin{array}{c}\text { Immediate } \\
\text { Recognition }\end{array}$ & $\begin{array}{c}\text { Delayed } \\
\text { Recognition }\end{array}$ \\
\hline Targets & Hit Rate & \\
PP & & \\
WW & .96 & 1.00 \\
PW & .87 & .95 \\
WP & .91 & .97 \\
& .87 & .92 \\
PP & $d^{\prime}$ & \\
WW & 3.55 & 3.44 \\
PW & 3.24 & 3.54 \\
WP & 3.28 & 3.51 \\
& 3.00 & 2.97 \\
Foils & False-Alarm Rate & \\
Picture & & .06 \\
Word & .02 & .02 \\
\hline
\end{tabular}

Note-Abbreviations explained in Table 1 note and in text.
As in Experiment 1, congruence between study and test facilitated recognition substantially. Also, studied pictures were at an advantage relative to studied words. Again, there was a facilitatory repetition priming effect on recognition speed between test probes of opposite modalities, but only from picture to word and not from word to picture.

An intriguing aspect of the accuracy data was the higher false-alarm rate for picture than for word foils. Against the background of the memorial superiority for pictures, this finding is at variance with the usually found mirror effect (Glanzer \& Adams, 1985). Wherever types of stimuli differ in their memory retention characteristics (such as pictures vs. words, concrete vs. abstract words, etc.), the general rule is that the type of stimulus that is more easily recognized as old, when old, is also more easily rejected as new, when new. Discussion of the reasons for this seeming inconsistency with earlier results will appear in later sections.

Importantly for the examination of the dual-encoding hypothesis, there was no facilitation of the transition into the opposite modality for items studied as pictures. According to the hypothesis, such facilitation should accompany memorial superiority for pictures, wherever such is found. Still, in both Experiment 1 and Experiment 2, studied pictures were more easily recognized, yet showed no evidence of being more often dually encoded than words.

In both experiments, the encoding, dual or otherwise, was not manipulated by instructions during study. In Experiment 3 , however, the effects of instructions to name studied items overtly was examined.

\section{EXPERIMENT 3}

Experiment 3 used a between-subject design to manipulate the encoding of studied items. In one condition, the silent-study group, instructions were the same as in the two previous experiments. In the other, the naming group, instructions were to name aloud each study item as it appeared on the screen. The effect of labeling pictures on their subsequent retrieval could therefore be studied directly.

Some other aspects of the procedure were also changed. Because the two previous experiments had revealed interesting differences in the false-alarm rates between the two foil modalities, we thought it important to acquire RT data for the foils as well. The task was therefore made into a choice RT task, with active responses required for both "yes" and "no" decisions.

\section{Method}

Subjects. Thirty-one students ( 15 men, 16 women) at the University of Lund participated. Their ages ranged from 20 to 33 years, with an average of 24 years. They were randomly assigned to the two study conditions (naming, 15; silent study, 16).

Materials and Procedure. Selection of items was preceded by an exploratory study, using 10 subjects (not participants in the experiment proper). They were asked to name all 260 pictures in the 
Snodgrass and Vanderwart set, to provide an estimate of the unanimity of verbal labeling in Swedish for each item. Only items with a minimum dominant-response probability of .9 were included in the ensuing experiment. A total of 120 items were selected and randomly assigned to the status of to-be-studied pictures $(20)$, to-be-studied words (20), picture foils (40), and word foils (40). In the test phase, average interitem lag between successive presentations of the same item in different formats was 52 .

Two keys on the keyboard (left arrow and right arrow) were assigned the role of "yes" and "no" keys, to be pressed with the left or the right index finger. The mapping of "yes" and "no" to left and right keys was counterbalanced over subjects.

The procedure in the silent-study condition was otherwise identical to that of Experiment 1 and the brief interval condition of Experiment 2 . In the naming condition, the subjects were additionally instructed to name aloud all items, both words and pictures, as they appeared on the screen during the study phase. In the few cases where a nondominant label was given by the subject at the first showing, it was corrected by the experimenter. The recognition test phase proceeded identically in the two conditions.

\section{Results}

Reaction time. RTs for correctly identified old items were subjected to a four-way ANOVA: study condition (between subjects) $\times$ congruence $\times$ study modality $\times$ repetition (the latter three all within-subject effects and identical to the ones studied in Experiments 1 and 2). As before, there was a reliable effect of study/test congruence $\left[\min F^{\prime}(1,90)=40.50, M S_{\mathrm{e}}=8,123\right]$, indicating an advantage for congruent presentations (833 vs. $993 \mathrm{msec}$ ).

Also, there was an effect of study modality $\left[\min F^{\prime}(1,101)=17.28, M S_{\mathrm{e}}=12,737\right]$, with studied pictures enjoying an advantage ( $855 \mathrm{vs.} 971 \mathrm{msec})$. In contrast to the earlier experiments, there was a main effect of repetition $\left[\min F^{\prime}(1,99)=10.43 ; 874\right.$ vs. $952 \mathrm{msec}$. The interaction of congruence $\times$ study modality $\times$ repetition, which had been reliable in earlier experiments, was so only in the by-subjects analysis $\left[F 1(1,29)=16.78, M S_{\mathrm{e}}=5,028\right]$ [whereas $F 2(1,72)=$ $3.25, p=.08$, and $\min F^{\prime}(1,94)=2.72, p=.10$ did not reach significance]. Study of the cell means in Table 5 reveals that the pattern of picture-to-word priming being more effective than word-to-picture priming was preserved, but the level of priming increased generally. Thus, word-to-picture priming was $41 \mathrm{msec}$, whereas it was negative in the two earlier experiments. Picture-toword priming was $116 \mathrm{msec}$. Differences in repetition effects between study conditions were not significant.

For the present study, a particular interest attaches to the translation costs. They were computed as in Experiments 1 and 2 (i.e., for unprimed items only) and were subjected to a two-way ANOVA, using study modality and study condition as factors. As before, study modality had a reliable effect, with larger translation costs for studied pictures (279 and $297 \mathrm{msec}$ for the naming and silent-study conditions, respectively). For studied words, the costs were $78 \mathrm{msec}$ in the naming condition and $14 \mathrm{msec}$ in the silent-study condition. Neither the main effect of study condition nor the study modality $\times$ study condition interaction ( $p=.15$ ) was significant.
Table 5

Reaction Times (in Milliseconds) in Experiment 3

\begin{tabular}{lccr}
\hline & $\begin{array}{c}\text { As First Test } \\
\text { Instance }\end{array}$ & $\begin{array}{c}\text { As Second Test } \\
\text { Instance }\end{array}$ & $\begin{array}{r}\text { Repetition } \\
\text { Effect }\end{array}$ \\
\hline \multicolumn{4}{c}{ Naming Condition } \\
Targets & \multicolumn{3}{c}{} \\
PP & 743 & 720 & 22 \\
WW & 1,012 & 859 & 153 \\
PW & 1,022 & 918 & 103 \\
WP & 1,090 & 1,016 & 74 \\
Foils & & & \\
Picture & 1,210 & & \\
Word & 1,069 & & \\
& Silent-Study Condition & \\
Targets & & & 103 \\
PP & 737 & 729 & 61 \\
WW & 983 & 880 & \\
PW & 1,034 & 932 & \\
WP & 997 & 937 & \\
Foils & & & \\
Picture & 1,227 & & \\
Word & 1,074 & & \\
\hline
\end{tabular}

Note-Abbreviations explained in Table 1 note and in text.

Returning to the main analysis, where both primed and unprimed items were included, there was a similar pattern, with a significant three-way interaction of congruence $X$ study modality $\times$ study condition $\left[F(1,29)=9.16, M S_{\mathrm{e}}=\right.$ $3,685]$. A follow-up Newman-Keuls test indicated that there was a difference between study conditions only for the WP stimuli (silent study, $967 \mathrm{msec}$; naming, 1,053 msec; $p<.001$ ). RTs for the PW stimuli did not differ (silent study, $983 \mathrm{msec}$; naming, $970 \mathrm{msec} ; p=.39$ ).

RTs for rejecting foils were examined in a two-way ANOVA, using modality and study condition as factors. Modality had a reliable effect $\left[\min F^{\prime}(1,90)=12.63\right.$, $\left.M S_{\mathrm{e}}=12,289\right]$ due to greater RTs for pictures $(1,219 \mathrm{msec})$ than for words $(1,072 \mathrm{msec})$. There was no difference between study conditions.

Accuracy. Hit rates, false-alarm rates, and $d$ 's are presented in Table 6. Analysis of $d$ 's revealed reliable effects of congruence $\left[F(1,29)=20.71, M S_{\mathrm{e}}=0.059\right]$, of study modality $\left[F(1,29)=26.32, M S_{\mathrm{e}}=0.248\right]$, and of their interaction $\left[F(1,29)=49.47, M S_{\mathrm{e}}=0.182\right]$. As in earlier studies, the lowest accuracy was associated with the WP category.

Differences between study condition groups were at the focus of interest in the present experiment. There was a study modality $\times$ study condition interaction, indicating that studied words were better recognized by the silent-study group (Newman-Keuls $p<.001$ ), but there was no difference between groups for studied pictures. Dual encoding should presumably have raised recognition accuracy for pictures in the naming group, but it failed to do so. Instead, overt naming seems to have prevented efficient memory encoding of studied words.

For false-alarm rates, foil modality made a difference $\left[\min F^{\prime}(1,107)=7.75, M S_{\mathrm{e}}=0.004\right]$. As before, and in agreement with the foil RT results, pictures were harder 
Table 6

Accuracy Data in Experiment 3

\begin{tabular}{ccc}
\hline & $\begin{array}{c}\text { Silent } \\
\text { Study }\end{array}$ & Naming \\
\hline Targets & Hit Rate & \\
PP & & \\
WW & .98 & .99 \\
PW & .94 & .86 \\
WP & .94 & .96 \\
& .92 & .83 \\
PP & $d^{\prime}$ & \\
WW & 3.30 & 3.06 \\
PW & 3.50 & 3.01 \\
WP & 3.49 & 3.55 \\
& 2.85 & 2.19 \\
Foils & False-Alarm Rate & \\
Picture & & .14 \\
Word & .07 & .03 \\
\hline
\end{tabular}

Note-Abbreviations explained in Table 1 note and in text.

to reject than words. There was also an interaction with study condition $\left[F(1,29)=4.84, M S_{\mathrm{e}}=0.004\right]$ due to a higher false-alarm rate for pictures in the naming group than in the silent-study group. Thus, the already elevated uncertainty about picture lures was increased by the naming procedure.

\section{Discussion}

The basic effects of study/test congruence and study modality showed consistency from earlier experiments, with congruence and pictorial study leading to more rapid recognition. In general, RTs were longer in Experiment 3 than in Experiments 1 and 2, possibly because the task involved a choice between two responses, instead of a go/no-go task. As a consequence, the amount of priming increased, obeying the principle that more time-consuming tasks benefit more from priming than do other tasks. The resulting pattern elevated the main effect of repetition into significance and reduced the congruence $X$ study modality $\times$ repetition to a borderline status, while preserving the pattern of asymmetry in cross-modal priming (picture-to-word $>$ word-to-picture).

The manipulation of naming during study led to no discernible effect on studied pictures. That could mean either that spontaneous naming is such a common occurrence that the instruction to do so does not add appreciably to its prevalence or, alternatively, that naming of pictures is not a helpful adjunct to their subsequent retrieval, be it intra- or cross-modally.

Instead, overt naming had a marked effect on the recognition of concepts studied as words. They were recognized more slowly in their pictorial guise, and less accurately overall, than they were under the silent-study condition. The effects indicate that encoding of words to deeper, semantic levels is disrupted by the access to the phonological code. Research within the sensorysemantic approach (Bajo, 1988) has also emphasized the finding that words can access their phonological code without semantic processing.

The mirror effect (Glanzer \& Adams, 1985) was again reversed. Pictures were rejected as new with greater difficulty (i.e., more slowly and less accurately) than were words, although pictures showed their usual superiority in being recognized as old. The reversed mirror effect can be explained by a two-stage recognition process (Jacoby \& Dallas, 1981; Mandler, 1980). Test probe items are first compared by virtue of their perceptual characteristics to perceptual records of studied items in a modality-specific store. If there is a match, the search terminates then and there. If, on the other hand, the probe is a cross-modally translated item, there can be no direct match, and a second search is initiated in a different memory store. For the time being, the question can be left open whether this other memory store is thought of as the semantic, amodal memory of the sensorysemantic model or the opposite-code store of the dualcode model. In either case, the encoding of studied pictures into memory will have been better than that of studied words. Therefore, the uncertainty attaching to picture foils will be relatively high, because they are matched against the weaker traces left by studied words. Word foils, on the other hand, are matched against the stronger traces left by studied pictures, and the computation will consequently run to an earlier and more accurate completion.

The mirror effect should therefore be reinstated if both formats of an item were presented together at study, because then it would always be possible to match a test probe against its proper perceptual record, and the second search stage could be eliminated. Experiment 4 tested, among other things, this prediction. But first, the effects found in Experiments 1-3 are briefly summarized below.

\section{SUMMARY OF EXPERIMENTS 1-3}

Temporarily disregarding the repetition effect, which will be further examined in Experiment 4, Table 7 reports average RTs for test stimulus types PP, WW, PW, and WP in Experiments 1-3. It also reports the magnitudes of three important effects in these experiments, obtained by calculating the appropriate contrast scores (Rosenthal \& Rosnow, 1985). The congruence effect (i.e., the advantage that accrues to testing in the studied format) proved to be reasonably consistent across experiments (in the range of 143-178 $\mathrm{msec}$ ). The advantage of studying items in picture format also showed consistency, although it was notably larger in the naming condition of Experiment 3, where the naming of study items aloud seems to have impaired semantic processing of words relative to pictures. A third effect was also examined: the advantage accruing to test items in picture format relative to those in word format. In the ANOVAs, the significance of this effect was tested as a congruence $\times$ study modality interaction, but, for clarity, it is reported 
Table 7

Average Reaction Times (in Milliseconds) for Stimulus Types in Experiments 1-3 and Effect Sizes (in Milliseconds) \pm Standard Errors of Contrast for

Effects of Study-Test Congruence, Study in Picture Format, and Test in Picture Format

\begin{tabular}{lllllclrr}
\hline & \multicolumn{4}{c}{ Stimulus Types } & & \multicolumn{2}{c}{ Picture } \\
\cline { 2 - 6 } \cline { 8 - 9 } Experiment & PP & WW & PW & WP & Congruence & Study & \multicolumn{1}{c}{ Test } \\
\hline 1 & 666 & 725 & 823 & 900 & $166 \pm 15$ & & $68 \pm 13$ & $-9 \pm 16$ \\
2 & 701 & 789 & 875 & 963 & $173 \pm 13$ & & $88 \pm 9$ & $0 \pm 10$ \\
3 (Silent study) & 733 & 932 & 983 & 967 & $143 \pm 15$ & $91 \pm 21$ & $107 \pm 11$ \\
3 (Naming) & 731 & 936 & 970 & 1,053 & $178 \pm 17$ & & $144 \pm 19$ & $61 \pm 11$ \\
\hline
\end{tabular}

Note-Abbreviations explained in Table 1 note and in text.

here in its own right. Pictorial test items were responded to faster than were word test items in Experiment 3 (both conditions), but not in Experiments 1 and 2. The reasons for this inconsistency are not self-evident, and we can only speculate that the greater difficulty of the choice reaction in Experiment 3, relative to the go/no-go response in Experiments 1 and 2, may have played a part. RTs were longer overall in Experiment 3, and this fact may have conferred advantages on factors that were relatively unimportant in Experiments 1 and 2.

\section{EXPERIMENT 4}

In Experiment 4, both word and picture were presented together for each item during study. During test, each format was presented alone, as before. One purpose of the manipulation was to test the assumption that the mirror effect would be reinstated. The experiment also had a different purpose. In Experiments 1-3, there were cross-modal priming effects from the first test item probing a studied concept to the second. Several questions arise concerning the priming effect. Is it strategic or automatic? Does cross-modal priming occur even if both perceptual representations of a studied item are available, making cross-modal connections strategically unnecessary? Furthermore, does priming occur, to an equal degree, for foils if they also appear twice during test, once in each format. If priming affects the same stage as recognition (i.e., takes place in the same store that holds the episodic memory of the study experience), then, by additive-factors logic (Sternberg, 1969), priming should interact with the target/foil status of the tested item.

Yet another purpose of Experiment 4 was to assess the importance of the perceptual format of the test probe on recognition speed. Are pictures recognized more quickly than words, when both perceptual representations are available in memory?

\section{Method}

Subjects. Fifteen psychology students ( 6 men, 9 women) at the University of Lund participated. Their ages ranged from 20 to 43 years.

Materials and Procedure. Items pretested for near-unanimous labeling were used (see Experiment 3). Of 80 selected items, 40 were randomly selected for the study list. During study, which otherwise took place as in the previous experiments, both a picture and its label were shown on the screen, the word below the picture.
The set of test items contained presentations in both picture and word format of both targets and foils. The sequence was arranged to give short interitem lags between cross-modal repetitions in order to allow a closer study of the repetition effects. The number of intervening items was zero in $25 \%$ of the cases, one item in $50 \%$ of the cases, and two items in $25 \%$ of the cases.

\section{Results}

Reaction times. All RTs for correct response (i.e., hits and correct rejections) were tested jointly in a threeway ANOVA, using test modality, target/foil status, and repetition as factors. Cell means are presented in Table 8.

There was a main effect of test modality $\left[\min F^{\prime}(1,52)=\right.$ $\left.21.76, M S_{\mathrm{e}}=8,947\right]$, indicating that pictures were recognized more rapidly than were words $(811 \mathrm{vs} .925 \mathrm{msec})$. The effect was not modified by any test modality $\times$ target/foil interaction (both $F 1$ and $F 2$ less than 1). Thus, there was a mirror effect for RTs in Experiment 4, in contrast to Experiment 3, in that recognition decisions were made more rapidly for pictures, both when they were old and new.

There was also a main effect of repetition $\left[\min F^{\prime}(1,70)\right.$ $\left.=32.30, M S_{\mathrm{e}}=6,189\right]$, because mean RT for primed items was $804 \mathrm{msec}$ (vs. $932 \mathrm{msec}$ for unprimed ones). Repetition priming interacted with test modality $\left[\min F^{\prime}(1,106)\right.$ $\left.=7.11, M S_{\mathrm{e}}=3,717\right]$. The priming effect for a word being preceded by its corresponding picture was much larger $(182 \mathrm{msec})$ than that for a picture being preceded by its verbal label $(73 \mathrm{msec})$. The pattern of picture-to-word priming, being larger than word-to-picture priming, was the same as that in earlier experiments.

The question whether priming effects extended to foils to the same degree as they did to targets can be answered by inspection of the repetition $\times$ target/foil interaction. It was significant in both by-subjects analysis $[F 1(1,14)=$ $\left.10.76, M S_{\mathrm{e}}=4,941\right]$ and by-items analysis $[F 2(1,152)=$

Table 8

Reaction Times (in Milliseconds) in Experiment 4

\begin{tabular}{lcrrrr}
\hline & \multicolumn{2}{c}{ Targets } & & \multicolumn{2}{c}{ Foils } \\
\cline { 2 - 3 } \cline { 5 - 6 } & Pictures & Words & & Pictures & Words \\
\hline As first test instance & 845 & 1,019 & & 851 & 1,013 \\
As second test instance & 734 & 790 & & 816 & 877 \\
Repetition effect & 111 & 229 & & 36 & 136 \\
\hline
\end{tabular}

Note--Abbreviations explained in Table 1 note and in text 
Table 9 Accuracy Data in Experiment 4

\begin{tabular}{lcc}
\hline & Pictures & Words \\
\hline Hit rate & 0.93 & 0.91 \\
False-alarm rate & 0.04 & 0.05 \\
$d^{\prime}$ & 3.47 & 3.12 \\
\hline
\end{tabular}

5.26], but the lower-bound $F$ ratio $\min F^{\prime}$ reached only marginal significance $\left[\min F^{\prime}(1,94)=3.53, p=.06\right]$. The results indicate that priming was more effective among targets $(170 \mathrm{msec})$ than among foils $(86 \mathrm{msec})$. A separate test revealed that differences in interitem lag had no significant effect.

Accuracy. Hit rates, false-alarm rates, and $d^{\prime}$ 's are given in Table 9. The $d^{\prime}$ measure was tested for effects of test modality $\left[F(1,14)=6.86, M S_{\mathrm{e}}=0.133\right]$ and found to be higher for pictures (3.47) than for words (3.12). The false-alarm rate, which had been markedly higher for pictures than for words in Experiments 1-3, was now reduced to 0.04 , below that for words $(0.05$; the difference was not significant).

The repetition of foils apparently led to no confusion in the subjects about whether they had seen an item earlier in the test or in the study phase, because false-alarm rates were only marginally and nonsignificantly different for foils appearing for the second time relative to their first appearance.

\section{Discussion}

Four questions were addressed in Experiment 4. First, does cross-modal repetition priming occur even when it is not strategically necessary-that is, when both perceptual formats have been made available during study, making conceptual translations unneeded? The answer was that it does occur. Priming was strong, and it showed the same asymmetry as in Experiments 1-3, being greater from picture to word than in the reverse direction.

Second, is priming greater for targets than for foils (i.e., does priming interact with newly formed episodic memory representations)? Again, the answer was affirmative. Here, the results concur with findings showing that nonwords, which normally do not benefit from repetition priming in the lexical decision task, acquire the capacity to do so through repeated exposure (i.e., through the formation and strengthening of episodic memory representations; see Salasoo, Shiffrin, \& Feustel, 1985). In general, our results support episodic interpretations of priming phenomena (Ratcliff \& McCoon, 1988).

Third, could the normally found mirror effect, which had been reversed in Experiments 1-3, be restored by making both perceptual formats available during study, thus short-circuiting strategic, conceptual processing out of the recognition process? It could. Picture foils, which had been responded to more slowly and less accurately in Experiments 1-3, were responded to more quickly and more accurately in Experiment 4 . The find- ing gives support to an interpretation of recognition, at least in the present task, as a two-stage process.

Fourth, what impact does the perceptual format of the test probe have on recognition speed? In Experiments $1-3$, this question was not given an unequivocal answer. Here, the effect of test modality was isolated from that of study modality, because, for each studied item, both modalities were presented, and the ensuing recognition decision could always be made on the basis of correspondence with a studied format. Recognition responses were made both more rapidly and more accurately for pictures. The result can be interpreted to mean that access to a semantic level is more rapid and effective for pictures than for words, in accordance with the sensory-semantic model. In contrast, it poses a challenge for explanations of the picture superiority effect that emphasize processes at study that distinguish the encoding of pictures from the encoding of words. Thus, in Snodgrass's model, picture superiority results from the combined effects of word polysemy (which distributes activation over several semantic nodes) and picture-prototype mismatch (which requires more elaborate encoding of pictures to arrive at a semantic interpretation of the perceptual input). In Experiment 4, both causes were removed by the combined presentation of picture and word. No elaborative encoding efforts had to be expended on matching the studied picture against a stored prototype to arrive at a unique semantic interpretation. Interpretation of the word was made unique in the present context by support from the accompanying picture.

\section{GENERAL DISCUSSION}

\section{Study-Test Congruence}

A recurring finding in these experiments was the relative ease with which test items congruent in presentation modality with their studied counterparts were recognized, in comparison with cross-modally translated items. The finding is in general agreement with many others from researchers who emphasize similarities between operations performed at study and at test as important determinants of memory performance (Roediger, 1990; Weldon, 1991; Weldon \& Roediger, 1987; Weldon et al., 1989). Bearing on the question of what is preserved in the memory code, the results strongly suggest that perceptual specifics, and not only an abstract semantic representation, are stored in memory. In this respect, the results agree well with the essence of dualcode theory. But theories such as those of Nelson et al. and Snodgrass, which basically assume a common semantic code, have also accommodated findings of this sort by postulating additional memory stores. In Tulving and Schacter's (1990) scheme, perceptual records are stored in a special presemantic memory system, which is independent of the separate episodic and semantic systems. In general, studies of priming have revealed that a wealth of perceptual details is often preserved in mem- 
ory, with a noteworthy duration (Jacoby \& Dallas, 1981) and specificity (Jacoby \& Hayman, 1987).

\section{Picture Superiority}

The second main finding of these experiments was the superior memory accessibility of items studied as pictures. With accuracy measures, the picture superiority effect is a well-known and extensively studied phenomenon. To our knowledge, this is the first time it has been demonstrated with a recognition latency measure.

In the recognition accuracy literature, the picture superiority effect has sometimes been found to be so strong as to override the study-test congruence (transferappropriate processing) effect. Thus, Madigan (1983) found that items studied as pictures were recognized better (in word format) than were items originally studied as words. In our study, we similarly found that hit rates for the PW category were higher than or equal to those for the WW category in Experiment 2 (both groups) and Experiment 3 (both groups). But with RT as the dependent variable, the congruence effect assumed dominance, and RTs for WW stimuli were generally shorter than those for PW stimuli. This dissociation between measures may reflect greater sensitivity to perceptual factors for recognition latency than for recognition accuracy.

For dual-code theories, image superiority is not a difficult fact to incorporate; indeed, it is one of the facts that started theory development (Paivio, 1991). But of the two proposed explanations, one (the dual-encoding hypothesis) does not accord well with the present findings. The pattern of RTs, especially the translation costs, was not consistent with implicit naming as the mediator of the effect, nor did instructions to overtly name pictures significantly enhance picture memorability. The other explanation (i.e., the hypothesis that the image code in itself is mnemonically superior to the verbal code) is, on the other hand, compatible with the results. A difficulty for dual-code theories is raised by the fact that memory for words was impaired by overt naming during study. This result suggests that words access their phonological code only at the expense of access to semantic features, yet dual-code theory seems to imply that phonological and semantic features are stored together in the verbal code, as are visual and semantic features stored together in the imaginal code.

Common-code theories have drawn attention to observed differences in access to the semantic code from pictures and words (Carr et al., 1982; Glaser \& Glaser, 1989; Nelson \& Castano, 1984; Nelson et al., 1977; Pellegrino, Rosinski, Chiesi, \& Siegel, 1977; Potter \& Faulconer, 1975; Smith \& Magee, 1980). Differential access is important to explain the memory results, because more processing at the semantic level can be expected to lead to better retention, especially when measured by direct memory tests. The present findings are consistent with better semantic access from pictures than from words as an explanation of the picture superiority effect.

The reasons for the superior access to a common semantic code from pictures are not clear, but some in- teresting observations have been contributed by investigations in recent years. Facilitatory effects from withincategory visual similarity have been known to contribute to categorization performance for pictures (Snodgrass \& McCullough, 1986). For example, most fruits have the same round overall shape, and perception of this feature may facilitate rapid categorization. However, some effects of visual similarity have been found for words as well (Job, Rumiati, \& Lotto, 1992). One interpretation of this fact is that some visual features are stored in the semantic code (e.g., round, along with other obvious features such as edible, sweet, etc., for fruit). Assuming a distributed representation, more features of the semantic representation of an object are then likely to be activated when a picture is encoded than when a word is encoded, because the visual features are presumably more strongly activated by the perception of a picture. This fact may contribute to the more rapid rise and the slower decay in activation of a semantic representation when activated from a picture than from a word.

In our results, more rapid access to the semantic level is additionally supported by observation of RTs to test items in Experiment 4, where studied items had been encoded both as pictures and as words, yet picture test probes showed consistently faster response times than did word test probes, both among targets and foils. Experiment 3 also showed an effect of test modality independently of study modality, with picture probes evoking faster responses than word probes, but Experiments 1 and 2 did not demonstrate the same effect. Differences in response organization (choice vs. go/no-go) may, at least in part, account for the discrepancy.

Theios and Amrhein (1989) have argued that stimulus size differences may affect processing speed and that comparisons of picture and word processing in the literature have often been confounded with size differences, pictures typically having been displayed larger than words. In our experiments, too, the pictures occupied a larger screen area than did the words. However, Theios and Amrhein did not find a linear effect of size on speed; with the three sizes they used $\left(1.5^{\circ}, 3^{\circ}\right.$, and $6^{\circ}$ of visual angle), they found that processing of the small stimuli was slowed down, but the size difference between the medium-sized and the large stimuli did not affect processing speed. In our study, the words, although smaller than the pictures, were displayed in a large enough typeface to occupy a viewing angle of about $3^{\circ}\left(4^{\circ}\right.$ for the pictures). On the basis of Theios and Amrhein's results, there is therefore no reason to believe that any of the stimuli were small enough to be delayed in processing because of size. Moreover, if any systematic effect of size were in operation, it would manifest itself as an effect of test modality (test words slower than pictures), but, although we used the same stimulus sizes throughout all four experiments, test modality had no effect in Experiments 1 and 2 . Thus, it appears unlikely that size differences between pictures and words could have played a significant part in our results. 


\section{Cross-Modal Priming}

There were effects of repeated testing in all experiments. The second testing of an item was affected by its predecessor, although the two instances had opposite perceptual formats, and could be separated by a large number of intervening items. Furthermore, the facilitatory effect of previous testing was much greater if the first instance was a picture than if it was a word. Not only was the repetition effect unexpectedly large in size, it also seemed to be evoked automatically, because it also appeared in Experiment 4, where there would seem to be no strategic need for cross-modal translations, both formats having been made available at study.

In the priming literature, there has been a strong tendency to regard priming as a data-driven and perceptually constrained phenomenon. Still, examples of crossmodal priming have repeatedly been found (Weldon, 1991; Weldon \& Roediger, 1987; Weldon et al., 1989), although they have typically been much smaller than intramodal effects. The cross-modal effects have aroused considerable interest, and further study has shown that they can be as great as the intramodal effects under some circumstances (Brown et al., 1991) and that they may affect such seemingly data-driven aspects of processing as perceptual information acquisition (Reinitz, Wright, \& Loftus, 1989) and fragment completion (Hirshman, Snodgrass, Mindes, \& Feenan, 1990).

The aspect of our priming results that is most in need of an explanation is the asymmetry of direction. It seems that more direct access to the semantic level from pictures than from words, as repeatedly observed in the literature, can make it more likely that the processing of a picture may leave its corresponding semantic node in a more activated state, ready to facilitate subsequent processing of the same concept, than would be the case if modalities were reversed. Therefore, extended commoncode theories such as that of Nelson and associates seem to be helpful in understanding the results. Within dualcode theories, priming has more rarely been discussed. The theory does, however, assume cross-modal (referential) connections between the two memory stores and allows for the possibility that connections in different directions may be unequally developed (Paivio, Clark, Digdon, \& Bons, 1989).

\section{The Mirror Effect}

In Experiment 4, where both modalities had been presented together at study, picture targets were more easily recognized as old than were word targets, and picture foils were more easily rejected as new than were word foils. This is the normal state of affairs, described as the mirror effect. In Experiments 1-3, however, picture foils were harder to reject, although picture targets were easier to recognize. The explanation we propose for this apparent discrepancy rests on regarding recognition as a two-stage process (Jacoby \& Dallas, 1981; Mandler, 1980). If the recognition decision can be based primarily on familiarity, as is the case when the test probe's perceptual format has been encountered during study, then the mirror effect obtains. If, however, direct familiarity is weak, a retrieval search has to be initiated, using semantic links to arrive at a concept studied under a different guise, then the success of the search depends crucially on the strength of the trace left by the studied item. Pictures leave stronger traces at deep processing levels; hence, a word test probe can be more easily matched against potential counterparts. For picture test probes, the matching process is more time-consuming and error-prone, because studied words have left less identifiable traces at deep levels.

This account of the mirror effect has borrowed some of its assumptions from modified common-code theories, but the same principle could also apply to dual-code theories, in which the image store is mnemonically superior to the verbal store, and referential connections are consulted in retrieval searches.

\section{Conclusions}

The findings of this study are compatible with modified common-code theories, such as the sensory-semantic model, that grant privileged access for pictures to a common semantic store. However, the results also indicate that much perceptual information is preserved in memory and that perceptual familiarity may play a greater part in recognition than is commonly acknowledged in these theories. The alternative dual-code theory proposes two explanations of the picture superiority effect, of which one (dual encoding) was not upheld by the results. Variants of the theory that assume better memory characteristics for the imaginal than for the verbal code are, on the other hand, compatible with the data. Extra assumptions concerning asymmetry of referential connections seem to be needed to explain the priming results in terms of dual-code theory. As discussed by Pellegrino et al. (1977), the two types of models may be difficult to separate on empirical grounds alone. At their present stage of development, some aspects of the theories are insufficiently constrained, and additional assumptions may be needed to fit them to new data. Ultimately, neuropsychological data may be needed to resolve some of the empirical issues concerning representation in memory. Hart and Gordon (1992) report such data, which they interpret to show a dual representation of knowledge in a verbal and an imaginal form. Whatever the state of the field will be when more facts have been accumulated, data on the representation of knowledge in the brain may eventually prove helpful in settling the issues.

\section{REFERENCES}

ANderson, J. R., \& Bower, G. H. (1973). Human associative memory. Washington, DC: Winston.

BAJO, M. T. (1988). Semantic facilitation with pictures and words. Journal of Experimental Psychology: Learning, Memory, \& Cognition, 14, 579-589.

Bisiach, E., \& LuzzaTTI, C. (1978). Unilateral neglect of representational space. Cortex, 14, 129-133.

Bousfield, W. A., Esterson, J., \& Whitmarsh, G. A. (1957). The effects of concomitant colored and uncolored pictorial representa- 
tions on the learning of stimulus words. Journal of Applied Psychology, 41, 165-168.

Brown, A. S., Neblett, D. R., Jones, T. C., \& Mitchell, D. B. (1991). Transfer of processing in repetition priming: Some inappropriate findings. Journal of Experimental Psychology: Learning. Memory, \& Cognition, 17, 514-525.

Carr, T. H., McCauley, C., Sperber, R. D., \& Parmelee, C. M. (1982). Words, pictures, and priming: On semantic activation, conscious identification, and the automaticity of information processing. Journal of Experimental Psychology: Human Perception \& Performance, $8,757-776$.

ClaRK, H. H. (1973). The language-as-fixed-effect fallacy: A critique of language statistics in psychological research. Journal of Verbal Learning \& Verbal Behavior, 12, 335-359.

Craik, F. I. M., \& Lockhart, R. S. (1972). Levels of processing: A framework for memory research. Journal of Verbal Learning \& Verbal Behavior, 11, 671-684.

Craik, F. I. M., \& Tulving, E. (1975). Depth of processing and the retention of words in episodic memory. Journal of Experimental Psychology: General, 104, 268-294.

FARAH, M. J. (1989). The neural basis of mental imagery. Trends in Neurosciences, 12, 395-399.

Farah, M. J., Weisberg, L. L., Monheit, M., \& Peronnet, F. (1989). Brain activity underlying mental imagery: Event-related potentials during mental image generation. Journal of Cognitive Neuroscience, 1, 302-316

GlANZER, M., \& ADAMS, J. K. (1985). The mirror effect in recognition memory. Memory \& Cognition, 13, 8-20.

GlASER, W. R., \& GLASER, M. O. (1989). Context effects in Stroop-like word and picture processing. Journal of Experimental Psychology: General, 118, 13-42.

Goldenberg, G., Podreka, I., \& Steiner, M. (1990). The cerebral localization of visual imagery: Evidence from emission computerized tomography of cerebral blood flow. In P. J. Hampson, D. F. Marks, \& J. T. E. Richardson (Eds.), Imagery: Current developments. London: Routledge.

HART, J., \& GORDON, B. (1992). Neural subsystems for object knowledge. Nature, 359, 60-64.

Hirshman, E., Snodgrass, J. G., Mindes, J., \& Feenan, K. (1990). Conceptual priming in fragment completion. Journal of Experimental Psychology: Learning, Memory, \& Cognition, 16, 634-647.

JACOBY, L. L., \& DALlas, M. (1981). On the relationship between autobiographical memory and perceptual learning. Journal of Experimental Psychology: General, 110, 306-340.

JACOBY, L. L., \& HAYMAN, C. A. G. (1987). Specific visual transfer in word identification. Journal of Experimental Psychology: Learning, Memory, \& Cognition, 13, 456-463.

JACOBY, L. L., \& WhitehouSE, K. (1989). An illusion of memory: False recognition influenced by unconscious perception. Journal of Experimental Psychology: General, 118, 126-135.

JoB, R., RUMIATI, R., \& LorTo, L. (1992). The picture superiority effect in categorization: Visual or semantic. Journal of Experimental Psychology: Learning, Memory, \& Cognition, 18, 1019-1028.

Kroll, J. F., \& Potter, M. C. (1984). Recognizing words, pictures, and concepts: A comparison of lexical, object, and reality decisions. Journal of Verbal Learning \& Verbal Behavior, 23, 39-66.

Madigan, S. (1983). Picture memory. In J. C. Yuille (Ed.), Imagery, memory, and cognition: Essays in honor of Allan Paivio (pp. 65-89). Hillsdale, NJ: Erlbaum.

MANDLER, G. (1980). Recognizing: The judgment of previous occurrence. Psychological Review, 87, 252-271.

Nelson, D. L., \& CASTANo, D. (1984). Mental representations for pictures and words: Same or different. American Journal of Psychology, 97, 1-15.

NeLSON, D. L., ReED, V. S., \& McEvoy, C. L. (1977). Learning to order pictures and words: A model of sensory and semantic encoding. Journal of Experimental Psychology: Human Learning \& Memory, 3, 485-497.

Paivio, A. (1971). Imagery and verbal processes. New York: Holt, Rinehart \& Winston.

PaIvio, A. (1986). Mental representations: A dual coding approach. Oxford: Oxford University Press.
PaIvio, A. (1991). Images in mind: The evolution of a theory. New York: Harvester Wheatsheaf.

Paivio, A., Clark, J. M., Digdon, N., \& Bons, T. (1989). Referential processing: Reciprocity and correlates of naming and imaging. Memory \& Cognition, 17, 163-174.

Paivio, A., \& Csapo, K. (1969). Concrete image and verbal memory codes. Journal of Experimental Psychology, 80, 279-285.

Paivio, A., \& Csapo, K. (1973). Picture superiority in free recall: Imagery or dual coding? Cognitive Psychology, 5, 176-206.

Pellegrino, J. W., Rosinski, R. R., Chiesi, H. L., \& Siegel, A. (1977). Picture-word differences in decision latency: An analysis of single and dual memory models. Memory \& Cognition, 5, 383-396.

POTTER, M. C. (1979). Mundane symbolism: The relation among objects, names, and ideas. In N. R. Smith \& M. B. Franklin (Eds.), Symbolic functioning in childhood (pp. 41-65). Hillsdale, NJ: Erlbaum.

Potter, M. C., \& FAulconer, B. A. (1975). Time to understand pictures and words. Nature, 253, 437-438.

Potter, M. C., \& LeVy, E. I. (1969). Recognition memory for a rapid sequence of pictures. Journal of Experimental Psychology, 81, $10-15$

PyLYShyn, Z. W. (1973). What the mind's eye tells the mind's brain: A critique of mental imagery. Psychological Bulletin, 80, 1-24

RATCLIFF, R., \& MCCoON, G. (1988). A retrieval theory of priming in memory. Psychological Review, 95, 385-408.

REINITZ, M. T., Wright, E., \& LofTus, G. R. (1989). Effects of semantic priming on visual encoding of pictures. Journal of Experimental Psychology: General, 118, 280-297.

RichardSON-KLAVEHN, A., \& BJoRK, R. A. (1988). Measures of memory. Annual Review of Psychology, 39, 475-543.

RoEDIGER, H. L., III (1990). Implicit memory: Retention without remembering. American Psychologist, 45, 1043-1056.

Rosenthal, R., \& Rosnow, R. L. (1985). Contrast analysis: Focused comparisons in the analysis of variance. Cambridge: Cambridge University Press.

Salasoo, A., Shiffrin, S. M., \& Feustel, T. C. (1985). Building permanent memory codes: Codification and repetition effects in word identification. Journal of Experimental Psychology: General, 114, 50-77.

SCHACTER, D. L. (1987). Implicit memory: History and current status. Journal of Experimental Psychology: Learning, Memory, \& Cognition, 13, 501-518.

SHAFFER, W. O., \& SHIFFrin, R. M. (1972). Rehearsal and storage of visual information. Journal of Experimental Psychology, 92, 292296.

SHEPARD, R. N. (1967). Recognition memory for words, sentences, and pictures. Journal of Verbal Learning \& Verbal Behavior, 6, 156-163.

SMITH, M. C., \& MAGEE, L. E. (1980). Tracing the time course of picture-word processing. Journal of Experimental Psychology: General, 109, 373-392

SNODGRASS, J. G. (1984). Concepts and their surface representations. Journal of Verbal Learning \& Verbal Behavior, 23, 3-22.

SNODGRass, J. G., \& CoRWIN, J. (1988). Pragmatics of measuring recognition memory: Applications to dementia and amnesia. Journal of Experimental Psychology: General, 117, 34-50.

SNOdGRass, J. G., \& MCCullough, B. (1986). The role of visual similarity in picture categorization. Journal of Experimental Psychology: Learning, Memory, \& Cognition, 12, 147-154.

SNODGRAss, J. G., \& VANDERWART, M. (1980). A standardized set of 260 pictures: Norms for name agreement, image agreement, familiarity, and visual complexity. Journal of Experimental Psychology: Human Learning \& Memory, 6, 174-215.

Standing, L., Conezio, J., \& Haber, R. N. (1970). Perception and memory for pictures: Single-trial learning of 2560 visual stimuli. Psychonomic Science, 19, 73-74.

STERNBERG, S. (1969). The discovery of processing stages: Extensions of Donders' method. Acta Psychologica, 30, 276-315.

Theios, J., \& Amrhein, P. C. (1989). Theoretical analysis of the cognitive processing of lexical and pictorial stimuli: Reading, naming, and visual and conceptual comparisons. Psychological Review, 96, 5-24.

Tulving, E., \& Schacter, D. (1990). Priming and human memory systems. Science, 247, 301-306. 
Tulving, E., \& Thomson, D. M. (1973). Encoding specificity and retrieval processes in episodic memory. Psychological Review, 80, 353-373.

WELDON, M. S. (1991). Mechanisms underlying priming on perceptual tests. Journal of Experimental Psychology: Learning, Memory, \& Cognition, 17, 526-541.

WELDON, M. S., \& RoEDiger, H. L., III (1987). Altering retrieval demands reverses the picture superiority effect. Memory \& Cognition, 15, 269-280.

Weldon, M. S., Roediger, H. L., III, \& Challis, B. H. (1989). The properties of retrieval cues constrain the picture superiority effect. Memory \& Cognition, 17, 95-105.

\section{APPENDIX}

Items Used in Experiments 1-4

\begin{tabular}{cl}
$\begin{array}{c}\text { Item } \\
\text { Number }\end{array}$ & \multicolumn{1}{c}{ Swedish } \\
\hline \multicolumn{2}{c}{ Experiment } \\
Items Studied as Pictures \\
13 & barnvagn \\
17 & bondgård \\
27 & cykel \\
49 & katt \\
64 & rock \\
73 & hund \\
83 & öra \\
84 & elefant \\
95 & boll \\
100 & groda \\
102 & soptunna \\
110 & gräshoppa \\
111 & gitarr \\
120 & helikopter \\
121 & häst \\
122 & hus \\
123 & strykjärn \\
126 & känguru \\
131 & stege \\
138 & glödlampa
\end{tabular}

Items Studied as Words

\begin{tabular}{rll}
1 & dragspel & accordion \\
2 & flygplan & airplane \\
3 & krokodil & alligator \\
18 & tunna & barrel \\
22 & säng & bed \\
39 & buss & bus \\
40 & fjäril & butterfly \\
43 & kamel & camel \\
68 & ko & cow \\
75 & åsna & donkey \\
81 & anka & duck \\
86 & öga & eye \\
89 & fisk & fish \\
103 & giraff & giraffe \\
107 & get & goat \\
108 & gorilla & gorilla \\
109 & vindruvor & grapes \\
117 & harpa & harp \\
129 & drake & kite \\
203 & skjorta & shirt \\
\hline
\end{tabular}

\section{Appendix (Continued)}

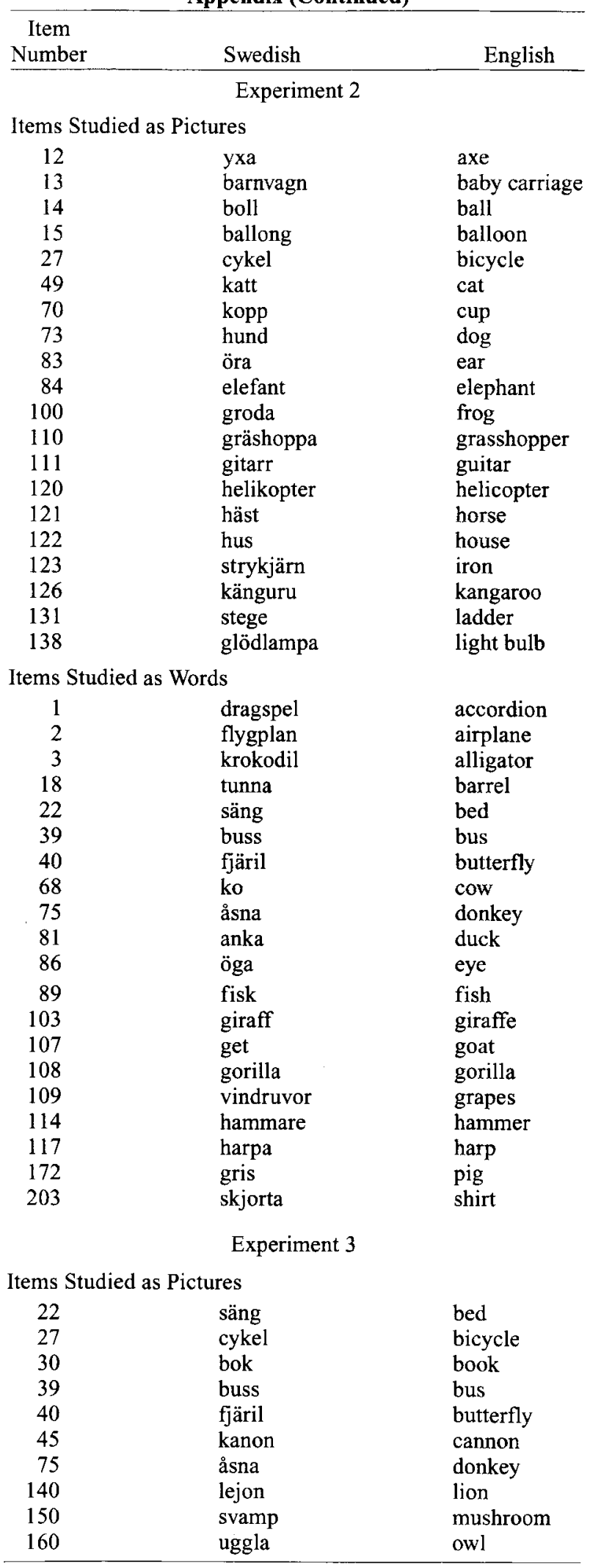


Appendix (Continued)

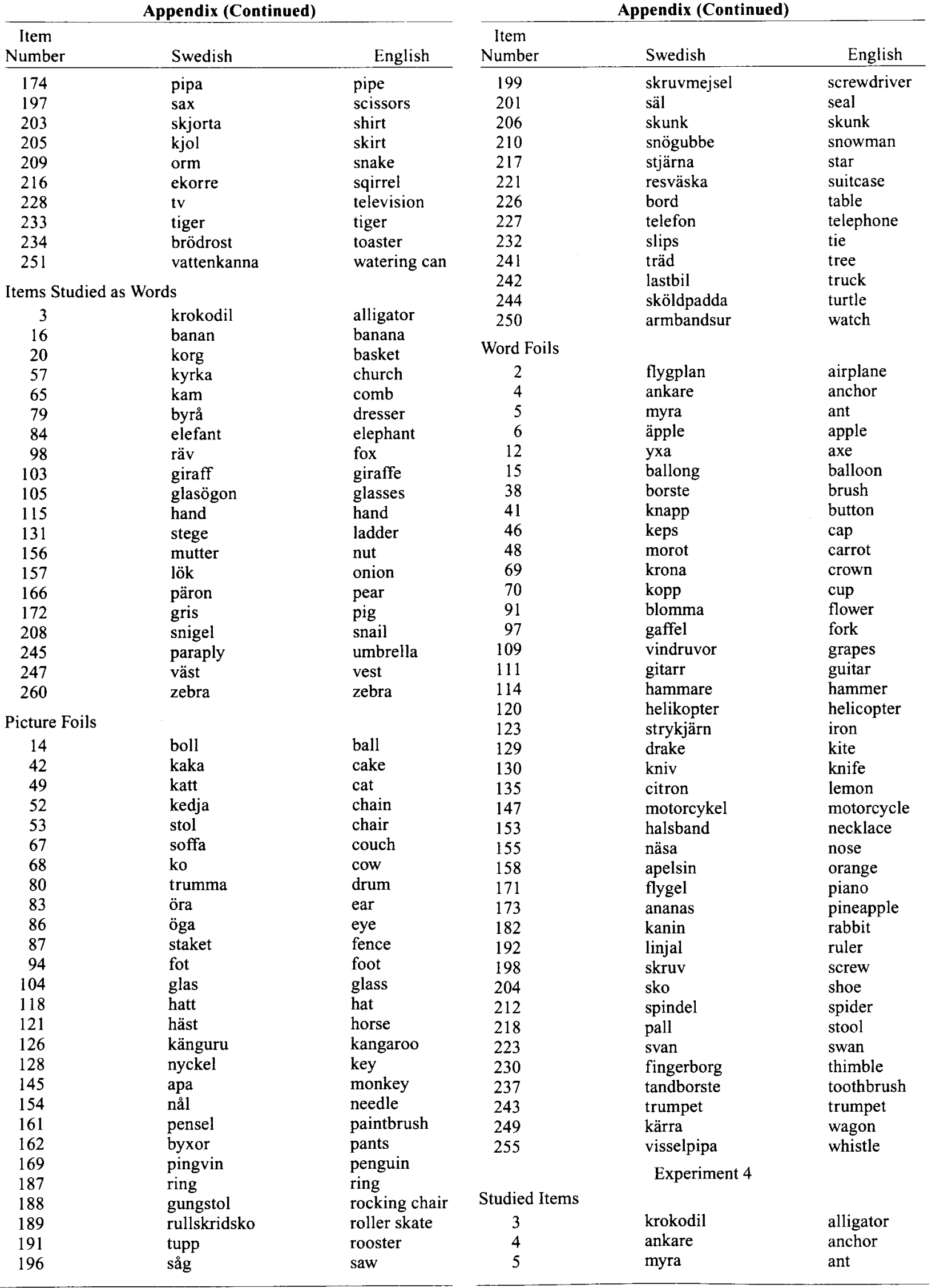


Appendix (Continued)

\begin{tabular}{|c|c|c|}
\hline $\begin{array}{c}\text { Item } \\
\text { Number }\end{array}$ & Swedish & English \\
\hline 6 & äpple & apple \\
\hline 15 & ballong & balloon \\
\hline 16 & banan & banana \\
\hline 20 & korg & basket \\
\hline 40 & fjäril & butterfly \\
\hline 45 & kanon & cannon \\
\hline 48 & morot & carrot \\
\hline 70 & kopp & cup \\
\hline 75 & åsna & donkey \\
\hline 83 & öra & ear \\
\hline 86 & öga & eye \\
\hline 91 & blomma & flower \\
\hline 97 & gaffel & fork \\
\hline 104 & glas & glass \\
\hline 111 & gitarr & guitar \\
\hline 118 & hatt & hat \\
\hline 121 & häst & horse \\
\hline 123 & strykjärn & iron \\
\hline 131 & stege & ladder \\
\hline 140 & lejon & lion \\
\hline 150 & svamp & mushroom \\
\hline 153 & halsband & necklace \\
\hline 156 & mutter & nut \\
\hline 161 & pensel & paintbrush \\
\hline 162 & byxor & pants \\
\hline 166 & päron & pear \\
\hline 172 & gris & pig \\
\hline 182 & kanin & rabbit \\
\hline 205 & kjol & skirt \\
\hline 226 & bord & table \\
\hline 227 & telefon & telephone \\
\hline 232 & slips & tie \\
\hline 234 & brödrost & toaster \\
\hline 237 & tandborste & toothbrush \\
\hline 244 & sköldpadda & turtle \\
\hline 245 & paraply & umbrella \\
\hline 247 & väst & vest \\
\hline \multicolumn{3}{|l|}{ Foils } \\
\hline 12 & yxa & axe \\
\hline 22 & säng & bed \\
\hline 27 & cykel & bicycle \\
\hline
\end{tabular}

Appendix (Continued)

\begin{tabular}{|c|c|c|}
\hline $\begin{array}{c}\text { Item } \\
\text { Number }\end{array}$ & Swedish & English \\
\hline 39 & buss & bus \\
\hline 41 & knapp & button \\
\hline 53 & stol & chair \\
\hline 57 & kyrka & church \\
\hline 65 & kam & comb \\
\hline 68 & ko & cow \\
\hline 84 & elefant & elephant \\
\hline 87 & staket & fence \\
\hline 94 & fot & foot \\
\hline 103 & giraff & giraffe \\
\hline 114 & hammare & hammer \\
\hline 126 & känguru & kangaroo \\
\hline 128 & nyckel & key \\
\hline 129 & drake & kite \\
\hline 135 & citron & lemon \\
\hline 145 & apa & monkey \\
\hline 154 & nål & needle \\
\hline 155 & näsa & nose \\
\hline 157 & lök & onion \\
\hline 160 & uggla & owl \\
\hline 169 & pingvin & penguin \\
\hline 174 & pipa & pipe \\
\hline 187 & ring & ring \\
\hline 188 & gungstol & rocking chair \\
\hline 192 & linjal & ruler \\
\hline 197 & $\operatorname{sax}$ & scissors \\
\hline 199 & skruvmejsel & screwdriver \\
\hline 203 & skjorta & shirt \\
\hline 208 & snigel & snail \\
\hline 209 & orm & snake \\
\hline 216 & ekorre & sqirrel \\
\hline 217 & stjärna & star \\
\hline 228 & tv & television \\
\hline 233 & tiger & tiger \\
\hline 243 & trumpet & trumpet \\
\hline 255 & visselpipa & whistle \\
\hline 260 & zebra & zebra \\
\hline Note- & om Snodgr & erwart (1980) \\
\hline
\end{tabular}

